\title{
A scientific note on the association of black fungus beetles (Alphitobius laevigatus, Coleoptera: Tenebrionidae) with Eastern honey bee colonies (Apis cerana)
}

\author{
Jakkrawut MaItIP ${ }^{1}$, Xuan ZhAng $^{2}$, Ken TAN ${ }^{2,3}$, Pham Hong ThaI ${ }^{4}$, Maxim V. NABOzhenko ${ }^{5}$, \\ Alexander G. KirejtshuK ${ }^{6,7}$, Panuwan Chantawannakul ${ }^{1}$, Peter NeumanN ${ }^{1,8,9}$

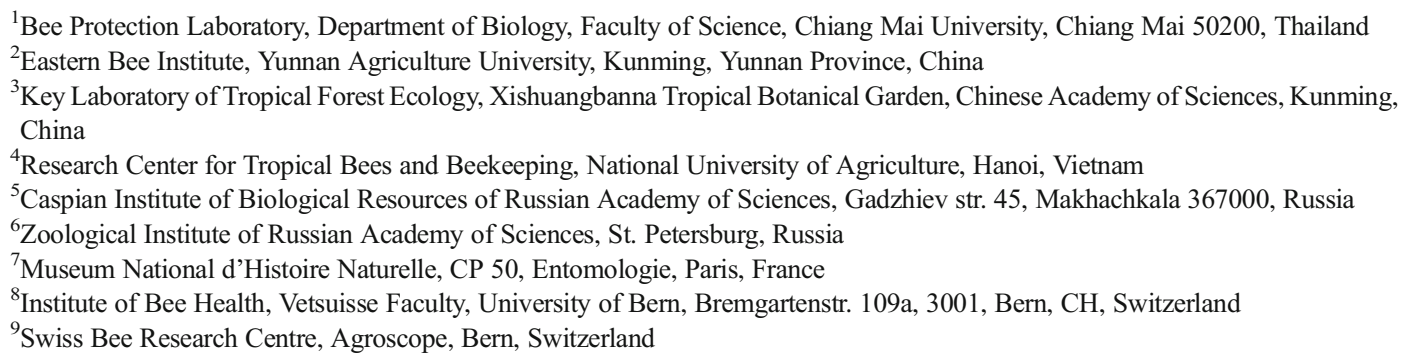

Received 13 June 2016 - Revised 16 July 2016 - Accepted 22 August 2016

A variety of beetle species can be associated with social bee colonies and may range from harmless associates to damaging parasites, thereby creating demand to better understand the nature of interactions between beetles and bees for each case (reviewed in Neumann et al. 2016). The black fungus beetle (=BFB; Alphitobius laevigatus (Fabricius, 1781), Coleoptera: Tenebrionidae; Figure 1a-c) is endemic to subSaharan Africa but currently has a cosmopolitan synanthropic distribution (Schawaller and Grimm, 2014). It is mycetophagous and known as a pest of various stored products (such as bread, flour products, rice, cocoa etc.; Medvedev 1974; Koch 1989; Rees 2004; among many others). Here, we report for the first time its association with colonies of the Eastern honey bee, Apis cerana .

Corresponding author: P. Chantawannakul, panuwan@gmail.com;

P. Neumann, peter.neumann@vetsuisse.unibe.ch Manuscript editor: David Tarpy
The adults of A. laevigatus share a considerable similarity to those of the lesser mealworm, A. diaperinus (Panzer, 1796), which has recently been reported to inhabit A. cerana colonies (Li et al. 2016). These two species can be separated from each other by the structure of their eyes (Rees 2004) and pronotum (Schawaller \& Grimm 2014). However, for a reliable discrimination, it is recommended to take into account the entire set of diagnostic morphometric characters (Abdurakhmanov \& Nabozhenko 2011):

A. diaperinus: The last six antennomeres are forming a separated club. The genal canthus halfway is projecting outwards beyond the contours of eyes. The pronotum is widest near the base and its lateral margins are weakly rounded, almost straight basally.

A. laevigatus: The last five antennomeres are forming a separated club. The eyes are almost divided by the genal canthus on dorsal and ventral halves with only some ommatidia between them. The pronotum is widest near the middle and its lateral margins are moderately regularly rounded. 


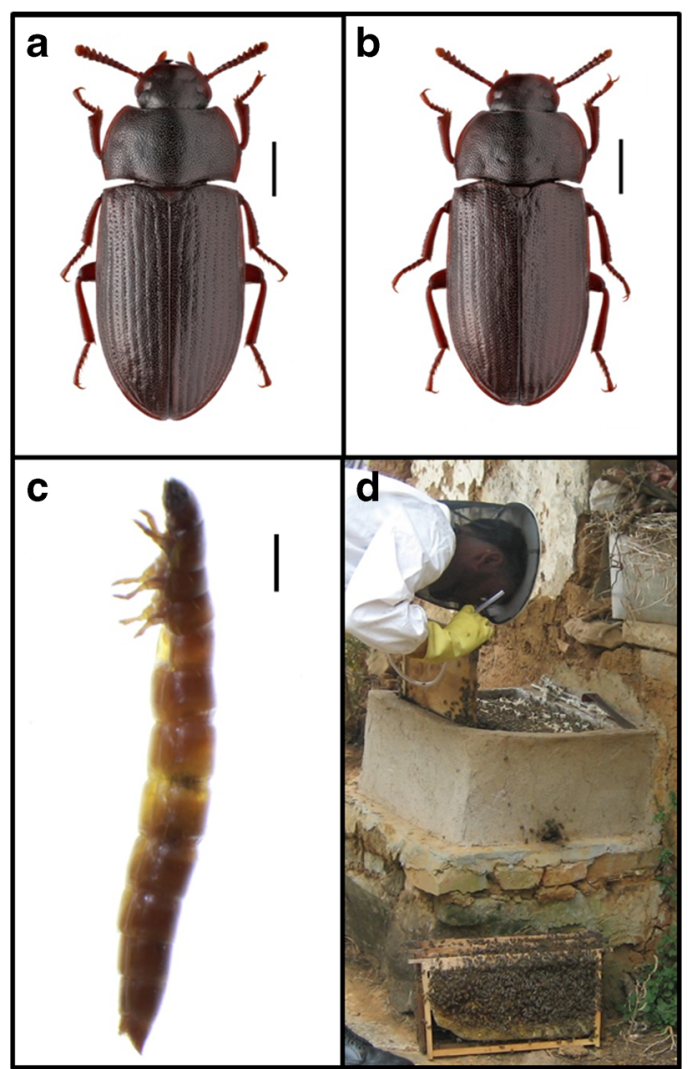

Figure 1 Black fungus beetles (Alphitobius laevigatus, Coleoptera: Tenebrionidae) in association with Eastern honey bee colonies, Apis cerana: a adult female; b adult male; $\mathbf{c}$ larva; $\mathbf{d}$ collection of beetles using aspirators during visual screening of A. cerana colonies housed in traditional clay hives in Wuding, Yunnan province (China); (scale bars in $\mathbf{a}, \mathbf{b}$, and $\mathbf{c}=1 \mathrm{~cm}$ ).

During casual colony inspections, adult BFBs were noticed on the bottom boards of Apis cerana hives in apiaries located around Hanoi (Vietnam) and Wuding (Yunnan province, China). The BFBs were manually collected using aspirators (Neumann et al. 2013, Figure 1d) and determined to be A. laevigatus (Coleoptera: Tenebrionidae) Figure 1a, b) using definitive morphometric characteristics (see above). In September 2015 (local autumn), adults of A. laevigatus $(N=25)$ were observed in $12 \mathrm{~A}$. cerana colonies in one apiary around Hanoi, Vietnam and collected for morphometric analyses. However, in March 2016 (local spring), careful visual inspections following Neumann et al. (2013) of 40 hives ( 3 apiaries) in the same area did not detect a single BFB in any hive, suggesting that the association of A. laevigatus with A. cerana colonies may fluctuate according to seasons at least in Vietnam. This matches personal communications with the local beekeepers about the presence of BFBs in hives.

In Wuding (Yunnan province, China, 25.94 ${ }^{\circ} \mathrm{N}, 104.27^{\circ}$ E), the hives of two traditional A. cerana apiaries (apiary 1: $N=10$; apiary 2: $N=16$ ) were visually screened during local summer for BFBs and detected specimens were collected using aspirators (Neumann et al. 2013; Figure 1d). Our aim was to get an accurate number of the total number of BFBs per colony as well as to have their spatial location determined. For that purpose, all frames were removed and carefully checked on both sides (Figure 1d), with bees pushed gently away using the aspirator when crowded. Similarly, all side walls and bottoms were carefully screened, with special attention given to holes, piles of debris and similar potential hiding opportunities for BFBs. In $57.7 \%$ of the colonies (apiary A: $N=7$; apiary B: $N=8$ ), a total of 113 adult BFBs were found (medians [1st; 3rd quartile] for infested colonies only; apiary $1: 6[3.5 ; 10.0]$; apiary $2: 3.5$ [2.0; 9.5]; overall: $4.0[2.5 ; 10.0])$, but neither beetle eggs/larvae nor any obvious signs of damage to colonies as known from small hive beetles, Aethina tumida, (Neumann et al. 2016) were found. The vast majority of adult BFBs $(N=110)$ was collected from the bottoms of the hives; only three adults were found on the clay hive walls and none on the combs. The BFBs caught on the hive walls may actually be an artefact of the sampling procedure, because similar to small hive beetles (PN, personal observations), the BFBs were also observed to run away during colony inspections. The preference of the bottoms of the hives is analogous to the distribution of adult $A$. tumida in Apis mellifera colonies, which also tend to prefer bottom boards (Neumann et al. 2016). Likewise, the adult BFBs were not evenly distributed among hives (Chi-square: $\operatorname{Sum} \chi^{2}=35.77, P<0.0001$, both apiaries pooled), which is also analogous to the uneven distribution of small hive beetles at $A$. mellifera apiaries (Neumann et al. 2016).

Our observations clearly show that $A$. laevigatus can be associated with A. cerana colonies in at least two Asian countries. The spatial preference of bottom boards in the field further suggests that these beetles are probably scavenging on various kinds of waste in the hives. Since none of the involved beekeepers reported any BFB-associated damage, A. laevigatus appears to be a rather harmless associate of $A$. cerana colonies. Nevertheless, the BFB may carry bee pathogens such as viruses similar to $A$. diaperinus in A. cerana colonies (Li et al. 2016) and effects on colonies may be seasonal and/or not obvious during visual inspections. Further detailed studies on A. laevigatus and other beetle 
associates will shed light on the underlying mechanisms enabling certain species, but not others, to exploit the usually well-defended social bee colonies as food sources and/or shelter.

\section{ACKNOWLEDGMENTS}

We wish to thank Chiang Mai University (PC, PN), Yunnan Agricultural University (TK, PN), and the Vinetum foundation (PN) for financial support as well as Daniel Schläppi and Kitiphong Khongphinitbunjong for technical support. The authors greatly appreciate the kind help of A.V. Kovalev (All-Russian Institute of Plant Protection, Pushkin) for the photographs of the specimens examined at the Zoological Institute of the Russian Academy of Sciences (Figure 1a, b). Two anonymous referees kindly provided constructive comments on an earlier version of the manuscript and Joseph Morris provided linguistic fine-tuning.

Authors' contributions PN initiated the study; JM, XZ, KT, PN conducted experiments; MN, AGK determined the species; KT, PHT, PC provided facilities; PN analysed data; $\mathrm{JM}, \mathrm{PN}$ wrote MS with input from all authors.

Note scientifique sur l'association des ténébrions des champignons, Alphitobius laevigatus (Coleoptera: Tenebrionidae) avec des colonies de l'abeille orientale (Apis cerana)
Eine wissenschaftliche Notiz zur Assoziation von Mattschwarzen Getreideschimmelkäfern (Alphitobius laevigatus, Coleoptera: Tenebrionidae) mit Völkern der östlichen Honigbiene (Apis cerana)

\section{REFERENCES}

Abdurakhmanov, G.S., Nabozhenko, M.V. (2011) Keys and catalogue to darkling beetles (Coleoptera: Tenebrionidae s. str.) of the Caucasus and the southern European part of Russia. KMK Scientific Press Ltd., Moscow. [In Russian].

Koch, K. (1989) Die Käfer Mitteleuropas. Ökologie. Bd 2. Goecke und Evers Verlag. Krefeld.

Li, Z., Huang, S., Huang, W.F., Geng, H., Zhao, Y., Li, M., Chen, Y., Su, S. (2016) A scientific note on detection of honeybee viruses in the darkling beetle (Alphitobius diaperinus, Coleoptera: Tenebrionidae), a new pest in Apis cerana cerana colonies. Apidologie, DOI: 10.1007/ s13592-016-0430-1

Medvedev, G.S. (1974) Fam. Tenebrionidae - darkling beetles. In: Insects and Acari - pests of agricultural crops. Vol. 2. Coleoptera. Leningrad: Nauka: 123-132. [In Russian]

Neumann, P., Evans, J.D., Pettis, J.S., Pirk, C.W., Schäfer, M.O., Tanner, G., Ellis, J.D. (2013) Standard methods for small hive beetle research. J. Apic. Res. 52(4),1-32

Neumann, P., Pettis, J.S., Schäfer, M.O. (2016) Quo vadis Aethina tumida? Biology and control of small hive beetles. Apidologie, 47(3): 427-466

Rees, D. (2004) Insects of stored products. CSIRO Publishing. Collingwood Victoria.

Schawaller W, Grimm R (2014) The genus Alphitobius Stephens (Coleoptera, Tenebrionidae, Alphitobiini) in Africa and adjacent islands. ZooKeys. 415: 169-190. 